\title{
Eclectic approach to anxiety disorders among rural children
}

\author{
Abordagem eclética a transtornos de ansiedade em crianças de zona rural
}

\author{
Atefeh Ahmadi, ${ }^{1,5}$ Mohamed Sharif Mustaffa, ${ }^{2}$ Ali Akbar Haghdoost, ${ }^{3}$ Syed Mohamed Shafeq Mansor ${ }^{4}$
}

\begin{abstract}
Introduction: Anxiety disorders in primary school-aged children negatively affect their mental health and psychological development. Available non-medical treatments for these conditions are time-consuming and expensive. In this context, eclectic therapy is a therapeutic approach that incorporates some therapeutic techniques and philosophies to create the ideal treatment. In this study, eclectic therapy consisted of art therapy and cognitive-behavioral therapy designed for children suffering from high level of anxiety in their middle childhood years. The therapy also included group guidance sessions for their mothers. The effectiveness of this intervention was examined in the study.

Methods: 61 students aged 9-12 years with high levels of anxiety participated in the study. Intervention $A(n=20)$ consisted of 9-hour eclectic therapy for children with 3-hour group guidance sessions for their mothers. Intervention $B(n=20)$ consisted of 9-hour eclectic therapy for children. There was also a control group $(n=21)$.

Results: Teacher ratings of children's mental health difficulties and self-report ratings of anxiety disorders indicated a significant difference from pretest to posttest, revealing a large effect size between the two interventions. Higher levels of pretest scores significantly predicted higher posttest scores for all domains of anxiety and mental health difficulties. Furthermore, age, gender, mothers working a 15 -hour day, mother's educational level, parental divorce rates, parental death, and family monthly income predicted therapy outcomes.

Conclusion: Results provide support for the effectiveness of eclectic art and CBT to improve children's mental health and reduce anxiety through changing thoughts, beliefs, emotions, and behaviors that may cause fear and anxiety.

Keywords: Anxiety disorders, children, Spence Children's Anxiety Scale, eclectic therapy, SDQ, CBT.
\end{abstract}

\section{Resumo}

Introdução: Transtornos de ansiedade em escolares afetam sua saúde mental e seu desenvolvimento psicológico. Tratamentos alternativos disponíveis consomem tempo e são dispendiosos. Nesse contexto, a terapia eclética é uma abordagem terapêutica que incorpora algumas técnicas e filosofias terapêuticas para criar o tratamento ideal. Neste estudo, terapia eclética consistiu de terapia artística e terapia cognitivo-comportamental (TCC) planejada para escolares com altos níveis de ansiedade. A terapia também incluiu sessões de orientação em grupo para as mães. A eficácia da intervenção foi examinada.

Métodos: 61 escolares com idade de 9-12 anos e altos níveis de ansiedade participaram do estudo. A intervenção $A(n=20)$ consistiu de 9 horas de terapia eclética para crianças com sessões de 3 horas de orientação em grupo para as mães. A intervenção $B(n=20)$ consistiu de 9 horas de terapia eclética para crianças. Houve também um grupo controle $(n=21)$.

Resultados: Escores atribuídos pelos professores às dificuldades de saúde mental das crianças e escores de ansiedade autoaplicados indicaram diferenças significativas entre resultados pré-teste e pós-teste, revelando grande tamanho de efeito entre as duas intervenções. Escores pré-teste maiores foram preditores significativos de escores pós-teste mais altos para todos os domínios de ansiedade e dificuldades de saúde mental. Idade, gênero, mães trabalhando 15 horas/dia, nível educacional da mãe, índice de divórcio, morte de um dos pais e renda familiar mensal foram preditores de desfechos da terapia.

Conclusão: Os resultados sugerem a eficácia de arte eclética e TCC para melhorar a saúde mental de crianças e reduzir a ansiedade através de mudança em pensamentos, crenças, emoções e comportamentos que possam causar medo e ansiedade.

Descritores: Transtornos de ansiedade, crianças, Spence Children's Anxiety Scale, eclectic therapy, SDQ, CBT.

\footnotetext{
${ }^{1}$ Faculty of Nursing and Midwifery, Kerman University of Medical Sciences, Kerman, Iran. ${ }^{2}$ Department of Counseling, Faculty of Cognitive Sciences and Human Development, Universiti Malaysia Sarawak, Kota Samarahan, Sarawak, Malaysia. ${ }^{3}$ Research Center for Modeling in Health, Institute for Futures Studies in Health, Kerman University of Medical Sciences, Kerman, Iran. ${ }^{4}$ Faculty of Education, Universiti Teknologi Malaysia, Skudai, Johor, Malaysia. ${ }^{5}$ Nursing Research Center, Kerman University of Medical Sciences, Kerman, Iran.

Submitted Jun 28 2016, accepted for publication Jan 032017.

Suggested citation: Ahmadi A, Mustaffa MS, Haghdoost AA, Mansor SS. Eclectic approach to anxiety disorders among rural children. Trends Psychiatry Psychother. 2017;39(2):88-97. http://dx.doi.org/10.1590/2237-6089-2016-0047
} 


\section{Introduction}

Anxiety disorders (AD) are among the most common prevalent psychiatric disorders among children in middle childhood. ${ }^{1}$ In fact, rural children seem to experience a higher prevalence of $A D$ compared to their urban peers. This higher prevalence could be explained by underlying differences in demographic characteristics and risk factors, such as higher rates of mental health impairment, poverty, as well as limited access to diagnostic, therapeutic, and counselling services. ${ }^{2}$ Cognitive consequences and behavioral side effects of $A D$ - and their tendency to become chronic - affect children's psychological development and their academic achievement at school. ${ }^{3}$

Although the treatment of $A D$ is of fundamental importance, some issues still arise regarding the application of related interventions in rural areas. Cognitive-behavioral therapy (CBT) has been considered the most common evidence-based non-medical approach to pediatric AD.4,5 CBT focuses on modifying abnormal thoughts and behaviors by applying several techniques and interventions. It targets negative thinking patterns to replace them with more adaptive behaviors and cognitions. ${ }^{6}$ Despite the fact that many children who are diagnosed with $A D$ undergo a successful CBT, others are less responsive to this method and show non-significant symptomatic remission after intervention or in follow-up sessions..$^{5,7-10}$ In addition, CBT has been underutilized and critiqued for being too verbal or abstract for the treatment of children. ${ }^{11}$ CBT may never be appropriate for very young children with limited vocabulary and difficulty in understanding some of its concepts. On the other hand, engagement in the therapeutic process is important for the child's learning and to prevent premature termination of therapy. It has been shown that child involvement in therapy indicates outcomes, especially in later stages of treatment. Thus, there is a need to modify CBT - which is an effective therapy for treating $A D$ in adults ${ }^{12}$ - for children who may not benefit from it. ${ }^{13}$ Furthermore, significant positive outcome is achieved by providing multiple therapy sessions, which is sometimes hard to run in rural remote settings. ${ }^{5}$ Despite the high prevalence of $A D$ among rural children, ${ }^{2}$ access to psychological treatment for $A D$ in rural remote communities ${ }^{14-16}$ - with poor distribution of qualified professionals and limited service availability due to geographic isolation - has been a concern for many years. ${ }^{2,17,18}$

\section{Intervention in this study}

In a few previous studies, the use of an eclectic approach to treat pediatric $A D$ was more effective than
CBT. ${ }^{19}$ In this research, eclectic therapy was inspired by Gardner's theory of multiple intelligences (1983, 2006). ${ }^{20,21}$ This theory justifies distinct intelligences representing different abilities, through which children with anxiety communicate, process their difficulties, and learn how to overcome their problems. ${ }^{22}$ Gardner defined intelligence as a biopsychological potential to process information that can be used to solve problems or create products that are of value in a culture. The Multiple Intelligence (MI) theory provides a better understanding of the variety and scope of human cognitive feats than do competing accounts. It also better explains the variety of performances among children based on their different intelligences. ${ }^{22}$ MI theory helps to tailor therapy methods to client preferences by proving an effective metatheory ${ }^{23}$ that offers a more flexible framework in the delivery of service to children and matches treatment to their abilities and strengths. ${ }^{24}$ Many counselors and psychotherapists have realized that the only path to correcting human issues does not exist. Consequently, a single theory cannot provide a solution to all human problems. ${ }^{25}$ Eclectic therapy uses more than one approach to psychotherapy, and, therefore, is sometimes called combination or integrative therapy. It may be the best approach when more than one cause of a disease or a problem is known. ${ }^{26,27}$ The most effective therapeutic techniques in eclectic therapy are integrated to create the best treatments to meet the needs of clients. Although the existence of a favorite theory is often common, all available options can be used. The key is to help a wider range of clinical populations to solve their problems as effectively, quickly, and applicably as possible. ${ }^{28}$ This therapy considers all dimensions of a client's life to fully approach the issue, including cultural contexts, social systems, interpersonal patterns, and biology. ${ }^{29}$

It seems that CBT in limited sessions is not sufficiently effective. Therefore, its application in remote rural areas is sometimes not advisable due to financial and time limitations. In this regard, to achieve more efficiency in our study, we designed an eclectic therapy combining art and CBT therapeutic elements for students and group guidance sessions for their parents to approach their AD. ${ }^{26,30} \mathrm{CBT}$ - which is the most common psychological intervention for children with $A D^{5}$ - was the dominant component of this study. It focused on modifying maladaptive behaviors and unrealistic cognitions in children with AD. ${ }^{31}$ It helps children to become aware of their core beliefs, thinking patterns, and the relationship between their emotions and thoughts with consequent behaviors. ${ }^{32}$ We also tried to implement CBT through art therapy, which was the second major component of our study. The activities 
included music, painting, physical movement, and plays in all sessions. We adopted the simultaneous eclectic approach in this study (use of two or more types of psychotherapies in each session - art therapy and CBT in our case). Children, especially the anxious ones, tend not to provide enough verbal communication in talk therapies. On the other hand, art allows them to reveal their thoughts, experiences, inclinations, and emotions that they usually find threatening. ${ }^{33}$ With the application of four art modalities in the therapy, this research tried to implement more effective CBT to improve children's self-awareness skills based on their intelligences.

In this study group, guidance consisted of a program designed to give parents an opportunity to discuss their children's common problems and issues related to their fears and anxieties. ${ }^{34,35}$ By holding group guidance sessions for parents before the first session of eclectic therapy, we expected to add benefits beyond the outcomes achieved by pure child therapy. ${ }^{36,37}$ These guidance sessions may enhance the effectiveness of therapy by improving parenting skills to recognize anxiety symptoms, helping their children emotionally, and managing behavioral problems. ${ }^{38}$ Children are emotionally dependent on their parents, imitate their behaviors, and are influenced by parental tensions, anxieties and fears. ${ }^{39}$ Therefore, parental awareness may improve the quality of psychotherapy.

\section{Identifying sociodemographic predictors of therapy outcome}

Identifying socio demographic predictors of therapy outcome is another key dimension of this research. ${ }^{40}$ Studies on sociodemographic predictors of therapy outcome in pediatric $A D$ have been surprisingly limited so $\mathrm{far}^{41}$ or resulted in few findings of clinical or theoretical significance. ${ }^{7}$ To the best of our knowledge, this study is the first one to investigate sociodemographic predictors of the six domains of anxiety.

Previous studies revealed that age, gender, and socioeconomic status could not predict the level of CBT response. ${ }^{40,42}$ Other similar research found that older children show less favorable treatment outcomes, and that gender, family monthly income, family composition (i.e., single- versus dual-parent household) were not predictive of treatment outcome. ${ }^{43,44}$ Unlikely, Reynolds, Wilson, Austin, and Hooper (2012) realized that younger children had a lower positive response rate to therapy. ${ }^{45}$

For the current study, we hypothesized that the level of anxiety along with mental health difficulties would significantly change by the end of interventions $A$ and $B$. In addition, we predicted that intervention $A$ would be more efficient than intervention B. Secondly, we hypothesized that sociodemographic factors could predict therapy outcome.

\section{Method \\ Participants}

Children with high levels of AD had been screened within the context of a larger study involving 600 students attending the four primary schools of Pontian, a rural district in the province of Johor in southern Malaysia. Sociodemographic characteristics of the initial sample included: $50.3 \%$ boys and $49.7 \%$ girls, age range $9-11$ years (mean $=10.17$ years, standard deviation $[S D]=0.77)$. Most of the participants had low socioeconomic status (88\% with incomes lower than 3000 Malaysian Ringgit (about 1000 US\$/month). At least $93.6 \%$ of them were from crowded families (families with 5 or more members) and most of them belonged to families with low parental education levels (89.2\% of fathers and $87.3 \%$ of mothers did not attend university).

Children and parents completed Spence Children's Anxiety Scale (SCAS) - child and parent versions, respectively. One SD above the mean of all scores was established as the cutoff score for both child and parent versions. Seventy-one students who scored above the cutoff in both versions were considered for therapy (this cutoff score is defined by the author of SCAS). 8 students who scored above the cutoff score on the obsessive-compulsive disorder (OCD) scale were excluded because $O C D$ sufferers respond better to specific treatments. ${ }^{46}$ Students were randomly placed in 3 intervention groups (control group, intervention A, and B). Only 2 students failed to attend all sessions and were removed from final data analysis. Finally, 61 were included in data analysis.

\section{Instruments}

SCAS-Malay (parent and child versions) ${ }^{47}$ are parent report and self-report inventories that were used to recognize children's AD. Thirty-eight items of the child version correspond directly with the parent version. They measure six subscales of $A D$ : separation anxiety disorder (SAD); social phobia; OCD; generalized anxiety disorder (GAD); panic and agoraphobia; and physical injury fear. The child version also includes six positive fillers. Items are rated on a 4-point Likert-type scale (never, sometimes, often, and always), and total scores range from 0-114. Respondents are supposed to circle the option that best describes the situation. Several 
studies using confirmatory and exploratory factor analysis have provided sufficient support for the validity of the instrument resembling those outlined in Diagnostic and Statistical Manual of Mental Disorders, 4th edition (DSM-IV). ${ }^{48}$ The internal reliability of SCAS has been high in most studies. Its psychometric properties have been acceptable in Malaysia, ${ }^{48}$ Australia, ${ }^{49}$ Cyprus, ${ }^{50}$ Japan, ${ }^{51}$ and Germany. ${ }^{52}$ Furthermore, its adaptation to Danish, ${ }^{53}$ Greek, Spanish English, Swedish, and Italian languages was successful. ${ }^{50,54}$

Strengths and Difficulties Questionnaire (SDQ) teacher report belongs to the family of mental health and global functioning measuring instruments. It is a brief behavioral screening questionnaire about 3-16 years olds. It is currently one of the most frequently used international screening instruments for children and adolescents in the area of mental health. SDQ versions (self-report, parent, teacher) have been translated and validated into more than 60 languages with acceptable psychometric properties. ${ }^{55}$ Advantages of SDQ - which include its brevity, ease of administration, coverage of positive and negative behaviors, good correlation of its subscales with the diagnostic categories in DSM-IV and International Classification of Diseases, version 10 (ICD-10), and its availability - have made it a widely used screening questionnaire in communities and clinical settings. ${ }^{56}$ Its 25 items are divided between 5 scales, 5 items each: conduct problems, emotional symptoms, hyperactivity/inattention, pro-social behavior, and peer relationship problems (which are the most important components of mental health). Four of these scales (emotional symptoms, conduct problems, hyperactivity and peer problems) can be added up to generate a 'total difficulty score' ranging from 0-40. In the current study, pro-social scale was not included. These symptom questions ask whether the respondent thinks the child or adolescent has problems with emotions, concentration, and behavior or is able to get along with other people. ${ }^{57}$

The sociodemographic information questionnaire included items about age, gender, socioeconomic status (parental educational level, family monthly income, and employment status of parents), lifetime events (parental death in the previous year, child's chronic disease, child's long term medication, and parental divorce) and familial factors (birth order and number of siblings).

\section{Procedure}

This cross sectional descriptive study was approved by the Ministry of Higher Education, Universiti Teknologi Malaysia, and Ministry of Education. At the school level, head principals signed research agreement forms. All psychologists who conducted the sessions were Malay master's students of Guidance and Counselling. They were trained on the implementation of the program by attending a one-day workshop and five educational meetings before the sessions. The treatment manual for eclectic therapy as well as group guidance sessions were reviewed and exercised by all of the trained counsellors. Their credentials after training were verified by the director of the university counselling center. Furthermore, sessions were randomly checked and all the reports were evaluated and confirmed by the heads of research. Control group students were allowed to attend counseling sessions after completing the study. Students in intervention groups were randomly divided into: intervention B - six 1.5-hour sessions (two sessions per week) of eclectic therapy for children ( $n=$ $20)$; intervention A - six sessions of eclectic therapy for children and two 1.5-hour sessions of group guidance for mothers $(n=20)$; and control $(n=21)$. Children in interventions $A$ and $B$ participated in 9 hours of eclectic therapy. Mothers of the children in intervention A had 3 hours of group guidance (two sessions).

All children and their teachers completed baseline and post intervention SCAS-child version and SDQ-teacher report, respectively. Teacher involvement in this study concerned their key position in identifying students' mental health problems. ${ }^{58}$ Intervention was administered based on "standard principles of psychological treatment."59 Session details were described by Ahmadi et al. ${ }^{47}$ Group guidance for mothers included:

- Session 1: introduction and discussion about $A D$ in children and their consequences, brief psychoeducation, importance of parental support and reinforcement, cognitive restructuring to reduce anxiety, enhancement of parenting behaviors, and contingency management to encourage brave behaviors.

- Session 2: extinction techniques to reduce avoidant behaviors, strategies to recognize and reduce parental anxiety, enhancement of communication skills, specific problem solving in the family, relapse prevention, and termination.

Three mothers declined due to the inability to take time off from their work.

\section{Results}

The sociodemographic characteristics of students in the screening phase are presented in Table 1 . This quasi experimental/cross sectional study involved 61 children with high level of anxiety in baseline. Of the 61 children, 24 were males (39.3\%) and 37 were females $(60.7 \%)$, averaging 10.72 years $(S D=0.88)$. One-way 
analysis of variance (ANOVA) revealed no significant differences between pretest SCAS and SDQ scores in the experimental groups, $F_{2,58}=0.31, p=0.73$ and $F_{2,58}$ $=1.73, \mathrm{p}=0.19$, respectively. The site (school) effect for SCAS and SDQ at baseline was not significant $F_{3,57}=$ $0.16, p=0.92$ and $F_{3,57}=0.28, p=0.83$, respectively.

\section{Therapy effectiveness}

Both interventions $A$ and $B$ led to significant changes between pre-tests and post-tests mean size for all domains of SCAS and SDQ scores. Tukey's posthoc tests revealed that both interventions significantly reduced the scores of overall anxiety, $S A D, O C D$, social phobia, fear, panic, and attention deficit/hyperactivity disorder (ADHD) domains $(p<0.005)$, while greater reduction was recorded for intervention $A$ compared to $B$. Intervention A $(p<0.005)$ and intervention $B$ $(p<0.05)$ significantly reduced the mean of Conduct problems scores compared to control group. Also, both interventions (with no considerable difference between them) led to significant drop in SDQ and Emotional problem scores $(p<0.005)$ compared to control group. Intervention $B$ showed significant higher posttest mean size scores for Peer problems domain compared to the other groups $(p<0.005)$ and a considerably lower reduction of Peer domain scores than the others ( $p<$ 0.005 ). Intervention $B$ group had considerably lower posttest level of GAD $(p<0.005)$ compared to the other groups (Table 2 ).

Cohen's $d$ and $r$ values were medium or large for all domains except for Conduct scale in interventions $A$ and $B$, and for Peer domain in intervention A.

Pretest SCAS scores (independent of intervention groups) significantly predicted posttest SCAS scores ( $p$ $<0.05$ for all domains). Lower degrees of $A D$ in pretests predicted lower levels of $A D$ in posttests.

\section{Effect of sociodemographic predictors of treatment outcome}

The following independent sociodemographic predictors on intervention outcome for all domains of SCAS and SDQ were measured by analysis of

Table 1 - Sociodemographic characteristic of students in real research

\begin{tabular}{|c|c|}
\hline Construct/subconstruct & $\%$ \\
\hline \multicolumn{2}{|l|}{ Age (years) } \\
\hline 9 & 22.7 \\
\hline 10 & 36.4 \\
\hline 11 & 40.3 \\
\hline \multicolumn{2}{|l|}{ Gender } \\
\hline Female & 53.8 \\
\hline Male & 46.2 \\
\hline \multicolumn{2}{|l|}{ Socioeconomic status } \\
\hline \multicolumn{2}{|l|}{ Father's educational level } \\
\hline Illiterate & 36.9 \\
\hline Degree & 52.8 \\
\hline Graduate & 5.6 \\
\hline Master & 3.4 \\
\hline $\mathrm{PhD}$ & 1.3 \\
\hline \multicolumn{2}{|l|}{ Mother's educational level } \\
\hline Illiterate & 31.6 \\
\hline Degree & 56.2 \\
\hline Graduate & 5.9 \\
\hline Master & 5.4 \\
\hline $\mathrm{PhD}$ & 1.0 \\
\hline \multicolumn{2}{|c|}{ Father's employment status } \\
\hline Yes & 93.2 \\
\hline No & 6.8 \\
\hline \multicolumn{2}{|l|}{ Family monthly income } \\
\hline$<3000 \mathrm{RM}$ & 88.3 \\
\hline 3000-5000RM & 7.3 \\
\hline$<5000 \mathrm{RM}$ & 4.4 \\
\hline
\end{tabular}

\begin{tabular}{lc}
\hline Construct/subconstruct & $\%$ \\
\hline Major lifetime past events & \\
Chronic disease & \\
$\quad$ Yes & 10.2 \\
No & 89.8 \\
Long term medication & \\
$\quad$ Yes & 12.4 \\
$\quad$ No & 87.6 \\
Parental divorce & \\
Yes & 7.5 \\
No & 92.5 \\
Parental death in the previous year & \\
Yes & 5.1 \\
No & 94.9 \\
Familial factors & \\
Birth order & \\
First & 28 \\
Second & 17.5 \\
Third & 22.9 \\
Fourth $\geq$ & 31.6 \\
Number of siblings & \\
0 & 1.7 \\
1 & 2.9 \\
2 & 10.7 \\
$3 \geq$ & 84.7 \\
Mother's working hours per day & \\
0 & 25.5 \\
$0-4$ & 33.3 \\
$4-8$ & 18 \\
$8 \geq$ & \\
\hline & \\
&
\end{tabular}

92 - Trends Psychiatry Psychother. 2017;39(2) 
covariance (ANCOVA): effects of age, gender, and family socioeconomic status (family monthly income, educational level of parents, and father employment status); lifetime events (parental divorce, parental death in the previous year, chronic illness, and long term medication); and familial factors (number of siblings, child's birth order, and mother's working hours per day). Covariates were calculated by relating pretest to posttest scores. That is the reason why we adopted separate models instead of multivariate analysis of covariance (MANCOVA). Assumptions of ANCOVA test (independent random sampling, multivariate normality, homogeneity of covariance matrix, linear relationship among dependent variables, interval or ratio dependent variables, independence of observation, categorical independent variables, adequate sample size, no statistical relationship between covariate and dependent variables, and absence of multicollinearity) were fulfilled. Significant models of prediction are presented in Table 3. Pairwise comparisons based on estimated marginal means yielded the following results: girls' peer problems after sessions were reduced more boys' $\left(F_{1,22}\right.$ $=10.53, \mathrm{p}<0.005)$; children born to mothers with $\mathrm{a}$ diploma responded better to therapy for mental health

Table 2 - Mean scores of SCAS and SDQ domains in pretests and posttests, ANOVA, and SMD results

\begin{tabular}{|c|c|c|c|c|c|c|c|c|c|}
\hline \multirow[b]{2}{*}{ Parameter } & \multicolumn{2}{|c|}{ Control group } & \multicolumn{2}{|c|}{ Intervention A group } & \multicolumn{2}{|c|}{ Intervention B group } & \multirow[b]{2}{*}{ p-value* } & \multirow{2}{*}{$\begin{array}{c}\text { SMD } \\
\text { intervention A } \\
\begin{array}{c}\text { Cohen's } d \\
(r)\end{array}\end{array}$} & \multirow{2}{*}{$\begin{array}{c}\text { SMD } \\
\text { intervention B } \\
\begin{array}{c}\text { Cohen's } d \\
(r)\end{array}\end{array}$} \\
\hline & Pretest score & Posttest score & Pretest score & Posttest score & Pretest score & Posttest score & & & \\
\hline SCAS & $54.50(8.12)$ & $53.38(12.65)$ & $53.83(8.96)$ & $38.38(11.06)$ & $56.38(12.43)$ & $24.69(9.57)$ & $<0.005$ & $1.53(0.60)$ & $2.85(0.81)$ \\
\hline Fears & $6.04(2.62)$ & $6.00(2.53)$ & $5.58(2.51)$ & $3.54(1.66)$ & $6.77(2.55)$ & $2.77(2.08)$ & $<0.005$ & $0.96(0.43)$ & $1.71(0.65)$ \\
\hline SAD & $9.17(3.23)$ & $9.71(3.73)$ & $9.50(3.31)$ & $7.25(3.40)$ & $10.23(4.00)$ & $4.85(1.57)$ & $<0.005$ & $0.67(0.31)$ & $1.77(0.66)$ \\
\hline GAD & $8.79(2.51)$ & $7.71(2.91)$ & $9.21(2.91)$ & $6.46(2.76)$ & $9.15(2.30)$ & $3.46(1.94)$ & $<0.005$ & $0.97(0.44)$ & $2.67(0.80)$ \\
\hline OCD & $10.17(2.61)$ & $10.29(3.07)$ & $9.17(3.11)$ & $7.75(2.80)$ & $7.46(2.50)$ & $4.92(2.98)$ & $<0.005$ & $0.48(0.23)$ & $0.92(0.42)$ \\
\hline Social & $9.96(2.49)$ & $8.21(3.18)$ & $10.00(2.20)$ & $6.42(1.64)$ & $9.46(2.84)$ & $4.23(1.58)$ & $<0.005$ & $1.84(0.68)$ & $2.27(0.75)$ \\
\hline Panic & $10.38(3.29)$ & $11.46(3.33)$ & $10.38(3.22)$ & $6.96(4.02)$ & $13.31(4.44)$ & $4.46(2.47)$ & $<0.005$ & $0.94(0.42)$ & $2.46(0.78)$ \\
\hline SDQ & $14.38(5.29)$ & $16.50(5.41)$ & $13.33(4.64)$ & $8.83(5.30)$ & $16.38(3.82)$ & $10.46(1.45)$ & $<0.005$ & $0.90(0.41)$ & $2.05(0.71)$ \\
\hline Emotion & $4.50(2.44)$ & $5.25(2.41)$ & $3.75(2.00)$ & $2.17(2.23)$ & 4.77 (1.69) & $1.77(0.43)$ & $<0.005$ & $0.74(0.35)$ & $2.43(0.77)$ \\
\hline Conduct & $3.04(1.57)$ & $3.33(1.46)$ & $2.50(1.50)$ & $2.08(1.71)$ & $3.31(2.21)$ & $2.54(0.77)$ & $<0.05$ & $0.26(0.12)$ & $0.46(0.22)$ \\
\hline ADHD & $3.96(1.85)$ & $4.63(2.06)$ & $3.96(2.03)$ & $2.21(2.08)$ & $4.38(2.14)$ & $0.62(0.50)$ & $<0.005$ & $0.85(0.39)$ & $2.42(0.77)$ \\
\hline Peer & $2.88(2.02)$ & $3.29(1.82)$ & $3.13(1.45)$ & $2.38(0.92)$ & $3.92(1.60)$ & $5.54(0.77)$ & $<0.005$ & $0.61(0.29)$ & $-1.29(-0.54)$ \\
\hline
\end{tabular}

Data presented as mean (standard deviation).

* Analysis of variance (ANOVA). Effect size is based on standardized mean difference (SMD).

$\mathrm{ADHD}=$ attention deficit/hyperactivity disorder; Fears = physical injury fears; GAD = generalized anxiety disorder; OCD = obsessive compulsive disorder; Panic = panic disorder; SCAS = Spence Children's Anxiety Scale; SAD = separation anxiety disorder; SD = standard deviation; SDQ = Strengths and Difficulties Questionnaire; SMD = standardized mean difference; Social = social phobia.

Table 3 - Significant models of anxiety disorders and mental health difficulties for sociodemographic factors by analysis of covariance

\begin{tabular}{ll}
\hline Independent variables & Significant models \\
\hline Gender & Peer domain: $F_{1,22}=10.53, p<0.005$ \\
Age & Panic disorder: $F_{3,20}=3.13, p<0.05$ \\
Educational level of mother & ADHD domain: $F_{3,20}=3.21, p<0.05$ \\
Family monthly income & SDQ: $F_{1,21}=6.01, p<0.05$ \\
Mother's working hours per day & Conduct domain: $F_{1,21}=7.81, p<0.05$ \\
& Peer domain: $F_{3,20}=3.21, p<0.05$ \\
& SCAS: $F_{3,18}=4.52, p<0.05$ \\
& SAD: $F_{3,18}=6.35, p<0.005$ \\
& GAD: $F_{3,18}=3.59, p<0.05$ \\
& OCD: $F_{3,18}=5.49, p<0.05$ \\
Parental divorce & Social phobia: $F_{3,18}=4.03, p<0.05$ \\
Parental death in the previous year & ADHD domain: $F_{3,18}=3.26, p<0.05$ \\
\hline
\end{tabular}

$A D H D=$ attention deficit/hyperactivity disorder; $G A D=$ generalized anxiety disorder; $O C D=$ obsessive compulsive disorder; $\mathrm{SAD}=$ separation anxiety disorder; SCAS = Spence Children's Anxiety Scale; SDQ = Strengths and Difficulties Questionnaire. 
difficulties (SDQ) - specifically for conduct problems when compared to children born to illiterate mothers $\left(F_{1,21}=6.01, p<0.05\right)$; children in low income families responded better to treatment of peer problems than children in middle income families $\left(F_{3,20}=3.21, p<\right.$ 0.05); children of stay-at-home mothers responded better to overall anxiety (SCAS) (SCAS: $F_{3,18}=4.52$, $p<0.05)$, SAD $\left(F_{3,18}=6.35, p<0.005\right), \operatorname{GAD}\left(F_{3,18}=\right.$ 3.59, $\mathrm{p}<0.05)$, and ADHD domains of SDQ treatment than children of mothers who worked more than 8 hours per day $\left(F_{3,18}=3.26, p<0.05\right)$; GAD in children of nondivorced parents were better treated than in children of divorced parents $\left(F_{1,22}=10.38, p<0.005\right)$; and finally, children who experienced parental death in the previous year were worse treated than children whose parents were still living $\left(F_{1,22}=5.00, p<0.05\right)$.

\section{Discussion}

The first aim of this quasi-experimental study was to test the effectiveness of eclectic therapy for middle childhood AD (we hypothesized that the application of an eclectic approach with parental involvement would deliver more changes in anxiety levels). Our second aim was to investigate sociodemographic predictors of treatment outcome.

The current study offers an important contribution to therapeutic research in pediatric $A D$ by presenting a successful example of transportability of a clinically developed treatment into an educational community. This study supports the effectiveness of eclectic art and $\mathrm{CBT}$ in reducing anxiety symptoms in a high-risk sample of school-aged children. Our most considerable finding is that the indicators of adherence to the intervention - both in terms of self-report $A D$ and in terms of teacher-reporting of mental health difficulties - were very positive. The only exception was for peer domain in intervention $B$. It is a promising finding that presents an appropriate therapeutic approach in rural remote areas that suffer from lack of service.

Despite our hypothesis that parental involvement would lead to better outcomes, intervention B showed larger effect sizes for all sub scales (the exception was for Peer problem scale). This finding is supported by some other research that indicated that the application of noneclectic therapies with parental involvement achieved no greater or small greater efficacy than interventions targeting only the children. ${ }^{41}$ Also, at least one study showed that child therapy without parent involvement demonstrated to be superior to therapies involving parents. ${ }^{60}$ Possible justifications may include: the training protocol for guidance sessions wasn't enough rich to help mothers reduce their children's anxiety; or some sociodemographic characteristics of mothers determined how much importance they give to their children's anxiety and its treatment (e.g., level of maternal education). Thus, superiority of parental involvement over eclectic therapy for children remains unclear.

It seems that freedom of expression in CBT through art helped children manage their anxious behaviors, stresses, and fears, therefore, helped them improve their self-awareness and self-esteem. ${ }^{61}$ All of the children attended six sessions. CBT and Art therapy combination is closer to natural child tendencies ${ }^{62}$ and make therapy attractive and enlivening for them. Also, the combination increased therapy effectiveness during these limited sessions compared to control group. Insufficient focus on conducting issues in this short-term therapy could not remarkably relieve the conduction of problems. Thus, the effect of the therapy for conducting the disorder was not achieved.

Interestingly, teacher reports on their students' mental health difficulties correlated with student reports of $A D$ in all three groups (control, intervention $A$, and B). However, although teachers report externalizing disorders more than internalizing disorders, ${ }^{58}$ they have an important role in the identification and organization of their students' AD. Also, they can use their expertise to appropriately refer students mental health services. ${ }^{63}$ Teachers are in a key position to identifying students' mental health problems based on their apparent manifestations as well as changes in school performance. ${ }^{58,63}$

The effect size for interventions in GAD, overall anxiety, social phobia, and panic was very large, whereas effect sizes stated in some meta-analytic review studies using art or CBT interventions (e.g., FRIENDS) were less than two. ${ }^{5,64}$ On the other hand, there were some studies with higher effect sizes, but they only focused on one type of AD. ${ }^{45}$

Some previous studies - which stated that psychological interventions in the early stages of anxiety, or in cases of mild anxiety, led to better outcomes than intervention for moderate or severe grades ${ }^{43}$ - supported the findings of this research. Moreover, other authors believed that higher levels of pre-therapy symptomatic severity could predict higher post-intervention severity, but not a lesser level of recovery. ${ }^{7}$

The understanding of treatment-response predictors helps modification and improvement of therapies. Research on these predictors of middle childhood $A D$ has been surprisingly limited. ${ }^{41}$ In this study, age, gender, mother's educational level, mother's working hours per day, parental divorce, and parental death in the previous year had a significant influence on the outcomes of the therapy. 
Some previous studies that focused on pre-CBT predictors of response found that age, gender, and socioeconomic status could not predict the level of response to the intervention. ${ }^{40}$ Another similar study showed that older-child age was associated with less favorable treatment response, but child sex, family income, family composition (i.e., single- versus dualparent household) were not predictive of treatment response. ${ }^{43}$ Reynolds et al. (2012) found that younger children showed less response to therapy. ${ }^{45}$ The results of this investigation seem to be valuable for the planning of therapeutic interventions regarding the sociodemographic characteristics of the clients. If child's characteristics are predictors of resistance to therapy, more sessions, extra techniques, or individual therapy would be required.

The high prevalence of anxiety (15.6\%) in this study justifies the need for the delivery of mental health care services in rural areas, taking into account the sociodemographic issues faced by the population these regions. The fulfillment of this need requires a shift from CBT delivery and individual therapy to group eclectic art and CBT for middle-childhood-aged children with AD. Schools are ideal contexts for this change because they are available sources in rural areas and often count on a school counselor.

Regular screening and preventative and therapeutic programs for pediatric $A D$ - such as eclectic art and CBT with or without family involvement - can improve children's incorporated skills, which may help reduce their level of AD. The demographic risk factors of therapy resistance shown in this research can be considered for future treatment planning. The reduction or elimination of these vulnerable factors, as far as possible, may increase the probability of success in response to the interventions and maintain their effects for longer periods. Flexibility in sessions and attention to the diverse needs of members in group therapy can result in greater achievements. For those children who fail to respond adequately to therapy, more individual or group sessions could be offered. ${ }^{65}$

\section{Limitations and implications}

One of the limitations of this study has to do with the lack of follow-up studies to show long-term effectiveness of therapy. Furthermore, although the applicability of this study to different situations and people is very high, generalization may be limited to similar populations from a demographic point of view. Self-, parent, and teacher reports are multiple informant data sources for this study. Although the best diagnostic method in children is reached via multiple informants, clinical interview can confirm the results for the instrumental phase of the procedures.

Our favorable outcomes may encourage therapists to match their therapeutic approaches to their clients' demands and characteristics, and help them overcome limitations of their practices. Intervention $B$ had the highest effect size for overall anxiety and GAD. In turn, social phobia showed the highest value in intervention $A$. These results may be practical for clinicians to approach $A D$ with the best specific methods.

\section{Conclusion}

The present study demonstrated that eclectic therapy provides a realistic service option for rural children who normally lack access to suitable services. Besides offering cost-effective services to families and service providers, it underscores the feasibility of implementing pluralistic therapy for pediatric anxiety in a regular child and adolescent educational setting.

\section{Acknowledgements}

The authors would like to thank the financial support from the Malay Ministry of Higher Education (MOHE) and Research Management Centre (RMC), Universiti Teknologi Malaysia (UTM; institutional grant VOT: 4F304).

\section{Disclosure}

No conflicts of interest declared concerning the publication of this article.

\section{References}

1. Abbo C, Kinyanda E, Kizza RB, Levin J, Ndyanabangi S, Stein DJ. Prevalence, comorbidity and predictors of anxiety disorders in children and adolescents in rural north-eastern Uganda. Child Adolesc Psychiatry Ment Health. 2013;7:21.

2. Anderson NJ, Neuwirth SJ, Lenardson JD, Hartley D. Patterns of care for rural and urban children with mental health problems. Portland, ME: Maine Rural Health Research Center; 2013. http:// muskie.usm.maine.edu/Publications/MRHRC/WP49-RuralChildren-Mental-Health.pdf

3. Mychailyszyn MP, Beidas RS, Benjamin CL, Edmunds JM, Podell JL, Cohen JS, et al. Assessing and treating child anxiety in schools. Psychol Sch. 2011;48:223-32.

4. Drake KL, Ginsburg GS. Family factors in the development, treatment, and prevention of childhood anxiety disorders. Clin Child Fam Psychol Rev. 2012;15:144-62.

5. James AC, James G, Cowdrey FA, Soler A, Choke A. Cognitive behavioural therapy for anxiety disorders in children and adolescents. Cochrane Database Syst Rev. 2013;6:CD004690.

6. Sones HM, Thorp SR, Raskind M. Prevention of post traumatic stress disorder. Psychiatr Clin North Am. 2011;34:79-94. 
7. Lundkvist-Houndoumadi I, Hougaard E, Thastum M. Pre-treatment child and family characteristics as predictors of outcome in cognitive behavioural therapy for youth anxiety disorders. Nord J Psychiatry. 2014;68:524-35.

8. James A, Soler A, Weatherall R. Cognitive behavioural therapy for anxiety disorders in children and adolescents. Cochrane Database Syst Rev. 2005;4: CD004690.

9. Öst LG. Cognitive behavior therapy for anxiety disorders: 40 years of progress. Nord J Psychiatry. 2008;62:5-10.

10. Victor AM, Bernat DH, Bernstein GA, Layne AE. Effects of parent and family characteristics on treatment outcome of anxious children. J Anxiety Disord. 2007;21:835-48.

11. Malchiodi CA, Rozum AL. Cognitive-behavioral and mind-body approaches. In: Malchiodi CA. Handbook of art therapy. 2nd edition. New York: Guilford; 2012. p. 89-103.

12. Otte C. Cognitive behavioral therapy in anxiety disorders: current state of the evidence. Dialogues Clin Neurosci. 2011;13:413-21.

13. Campbell MA. Innovative ways to assist young anxious children. In Wilkie W, ed. Sensitivity and childhood trauma. Clear Mountain: Amanda Flynn Foundation; 2009. p. 76-88.

14. Smokowski PR, Cotter KL, Robertson CI, Guo S. Anxiety and aggression in rural youth: baseline results from the rural adaptation project. Child Psychiatry Hum Dev. 2013;44:479-92.

15. Sridevi K. A study of relationship among general anxiety, test anxiety and academic achievement of higher secondary students. J Educ Pract. 2013;4:122-30.

16. Yen $\mathrm{CF}$, Ko CH, Wu YY, Yen JY, Hsu FC, Yang P. Normative data on anxiety symptoms on the Multidimensional Anxiety Scale for children in Taiwanese children and adolescents: differences in sex, age, and residence and comparison with an American sample. Child Psychiatry Hum Dev. 2010;41:614-23.

17. American Psychiatric Association. Diagnostic and Statistical Manual of Mental Disorders, Fifth Edition (DSM-5). Arlington: American Psychiatric Publishing; 2013.

18. Lyneham HJ, Rapee RM. Childhood anxiety in rural and urban areas: presentation, impact and help seeking. Aust J Psychol. 2007;59:108-18.

19. Vakilian S, Ghanbari BA. Effectiveness of compound group cognitive-behavioral therapy and social skill training on fear of negatitive assessment and social avoidance. J Clin Psychol. 2009;1:11-28.

20. Gardner H. Frames of mind: Theory of multiple intelligences. London: Heinermann; 1983.

21. Gardner. H. Multiple intelligences. New horizons. New York: Basic Books; 2006.

22. Gardner $\mathrm{H}$, Moran $\mathrm{S}$. The science of multiple intelligences theory: a response to Lynn Waterhouse. Educ Psychol. 2006;41:227-32.

23. Cooper $M$. The challenge of counselling and psychotherapy research. Couns Psychother Res. 2010;10:183-91.

24. Pearson, M. Multiple intelligences, eclecticism and the therapeutic alliance: New possibilities in integrative counsellor education. BeyondSCAPE: Possibility and necessity in counselling and psychotherapy education. 2012.

25. Lazarus AA, Beutler LE. On technical eclecticism. J Couns Dev. $1993 ; 71: 381-5$.

26. Shilling HN. How integrative and eclectic therapists make treatment selection decisions: a qualitative study [dissertation]. Madison: University of Wisconsin; 2012.

27. Prochaska JO, Norcross JC. Systems of psychotherapy: a transtheoretical analysis. 7th ed. Pacific Grove: Brooks/Cole; 2010.

28. Norcross JC. A primer on psychotherapy integration. In: Norcross JC, Goldfried MR, editors. Handbook of psychotherapy integration. New York: Oxford University; 2005.

29. Brooks-Harris JE. Integrative multitheoretical psychotherapy. Boston: Houghton-Mifflin; 2008.

30. Taylor OD. Children of substance-abusing or substance-dependent parents. J Hum Behav Soc Environ. 2011;21:727-43.

31. Paul J. Evaluating the impact of a universal FRIENDS for Life Programme on emotional distress and academic self-perceptions [dissertation]. Nottingham: University of Nottingham; 2011.

32. Buchalter S. Raising self-esteem in adults: an eclectic approach with art therapy, CBT and DBT based techniques. London: Jessica Kingsley Publishers; 2014.

33. Wethington HR, Hahn RA, Fuqua-Whitley DS, Sipe TA, Crosby AE, Johnson RL, et al. The effectiveness of interventions to reduce psychological harm from traumatic events among children and adolescents: asystematicreview. Am JPrev Med. 2008;35:287-313.

34. Babatunde JO, Osakinle EO. Effects of group guidance and counselling techniques on students'vocational maturity in ekiti state secondary schools, Ekiti State, Nigeria. Eur Sci J. 2013;9478-84.

35. Owuamanam T. A handbook of guidance and counselling. Revised Ed. Lagos: Bolabay Publications; 2007.

36. Dowell KA, Ogles BM. The effects of parent participation on child psychotherapy outcome: a meta-analytic review. J Clin Child Adolesc Psychol. 2010;39:151-62.

37. Pahl KM, Barrett PM, Gullo MJ. Examining potential risk factors for anxiety in early childhood. J Anxiety Disord. 2012;26:311-20.

38. Cohen JA, Bukstein O, Walter H, Benson RS, Chrisman A, Farchione TR, et al. Practice parameter for the assessment and treatment of children and adolescent with posttraumatic stress disorder. J Am Acad Child Adolesc Psychiatry. 2010;49:414-30.

39. Liu J, Chen X, Lewis G. Childhood internalizing behaviour: analysis and implications. J Psychiatr Ment Health Nurs. 2011;18:884-94.

40. Knight A, McLellan L, Jones M, Hudson J. Pre-treatment predictors of outcome in childhood anxiety disorders: a systematic review. Psychopathol Rev. 2014;1:77-129.

41. Rapee RM. Family factors in the development and management of anxiety disorders. Clin Child Fam Psychol Rev. 2012;15:69-80.

42. Nilsen TS, Eisemann M, Kvernmo S. Predictors and moderators of outcome in child and adolescent anxiety and depression: a systematic review of psychological treatment studies. Eur Child Adolesc Psychiatry. 2013;22:69-87.

43. Southam-Gerow MA, Kendall PC, Weersing VR. Examining outcome variability: correlates of treatment response in a child and adolescent anxiety clinic. J Clin Child Psychol. 2001;30:422-36.

44. Rapee RM, Schniering CA, Hudson JL. Anxiety disorders during childhood and adolescence: origins and treatment. Annu Rev Clin Psychol. 2009;5:311-41.

45. Reynolds S, Wilson C, Austin J, Hooper L. Effects of psychotherapy for anxiety in children and adolescents: a meta-analytic review. Clin Psychol Rev. 2012:32:251-62.

46. Barrett PM, Farrell L, Pina AA, Peris TS, Piacentini J. Evidencebased psychosocial treatments for child and adolescent obsessivecompulsive disorder. J Clin Child Adolesc Psychol. 2008;37:131-51.

47. Ahmadi A, Mustaffa MS, Haghdoost A, Khan A, Latif AA. Crosscultural adaptation of the Spence Children's Anxiety Scale in Malaysia. Trends Psychiatry Psychother. 2015;37:37-41.

48. Ahmadi A, Mustaffa MS, Udin A, Haghdoost A. DSM-IV-defined anxiety disorder symptoms in a middle-childhood-aged group of Malaysian children using the Spence Children's Anxiety Scale. Trends Psychiatry Psychother. 2016;38:14-22.

49. Spence SH, Barrett PM, Turner CM. Psychometric properties of the Spence Children's Anxiety Scale with young adolescents. J Anxiety Disord. 2003;17:605-25.

50. Essau CA, Anastassiou-Hadjicharalambous $X$, Muñoz LC Psychometric properties of the Spence Children's Anxiety Scale (SCAS) in Cypriot children and adolescents. Child Psychiatry Hum Dev. 2011;42:557-68.

51. Ishikawa $S$, Sato $H$, Sasagawa $S$. Anxiety disorder symptoms in Japanese children and adolescents. J Anxiety Disord. 2009;23:104-11.

52. Essau CA, Muris $P$, Ederer EM. Reliability and validity of the Spence Children's Anxiety Scale and the screen for child anxiety related emotional disorders in German children. J Behav Ther Exp Psychiatry. 2002;33:1-18.

53. Nauta MH, Scholing A, Rapee RM, Abbott M, Spence SH, Waters A. A parent-report measure of children's anxiety: psychometric properties and comparison with child-report in a clinic and normal sample. Behav Res Ther. 2004;42:813-39.

54. Hernández-Guzmán L, Bermúdez-Ornelas G, Spence $\mathrm{SH}$, Montesinos MJG, Martínez-Guerrero JI, Villalobos JA, et al. Versión en español de la Escala de Ansiedad para Niños de Spence (SCAS). Rev Latinoam Psicol. 2010;42:13-24.

55. Richter J, Sagatun $\AA$, Heyerdahl S, Oppedal B, Røysamb E. The Strengths and Difficulties Questionnaire (SDQ) - self-report. An analysis of its structure in a multiethnic urban adolescent sample. J Child Psychol Psychiatry. 2011;52:1002-11.

56. Shahrivar Z, Tehrani-Doost M, Pakbaz B, Rezaie A, Ahmadi F. Normative data and psychometric properties of the parent and teacher versions of the strengths and difficulties questionnaire (SDQ) in an Iranian community sample. J Res Med Sci. 2009; $14: 69-77$.

57. Goodman A, Goodman R. Population mean scores predict child mental disorder rates: validating SDQ prevalence estimators in Britain. J Child Psychol Psychiatry. 2011;52:100-8.

58. Headley C, Campbell MA. Teachers' recognition and referral of anxiety disorders in primary school children. Aust J Educ Dev Psychol. 2011;11:78-90. 
59. American Psychological Association. Ethical principles of psychologists and code of conduct. 2010

60. Bodden $\mathrm{DH}$, Bögels SM, Muris P. The diagnostic utility of the screen for child anxiety related emotional disorders-71 (SCARED-71). Behav Res Ther. 2009;47:418-25.

61. Rabin AS. The experiences of children who participate in therapy incorporating art as a therapeutic medium. California: Alliant International University; 2012.

62. Rubin JA. Child art therapy. Hoboken: John Wiley \& Sons; 2011.

63. Loades ME, Mastroyannopoulou K. Teachers' recognition of children's mental health problems. Child Adolesc Ment Health. 2010;15:150-6.

64. Campbell ER. The effectiveness of art therapy in reducing symptoms of trauma, anxiety, and stress: a meta-analysis [dissertation]. Wheaton: Wheaton College; 2010.
65. Pereira AI, Marques T, Russo V, Barros L, Barrett P. Effectiveness of the friends for life program in portuguese schools: study with a sample of highly anxious children. Psychol Sch. 2014;51:647-57.

\section{Correspondence:}

Mohamed Sharif Mustaffa

Faculty of Nursing and Midwifery, Department of Counseling

Faculty of Cognitive Sciences and Human Development

Universiti Malaysia Sarawak

94300 Kota Samarahan

Sarawak, Malaysia

Tel.: +6-082-581531

E-mail: msharif@fcs.unimas.my 